\title{
Organizadiones Chinas Guanxi es más que networking
}

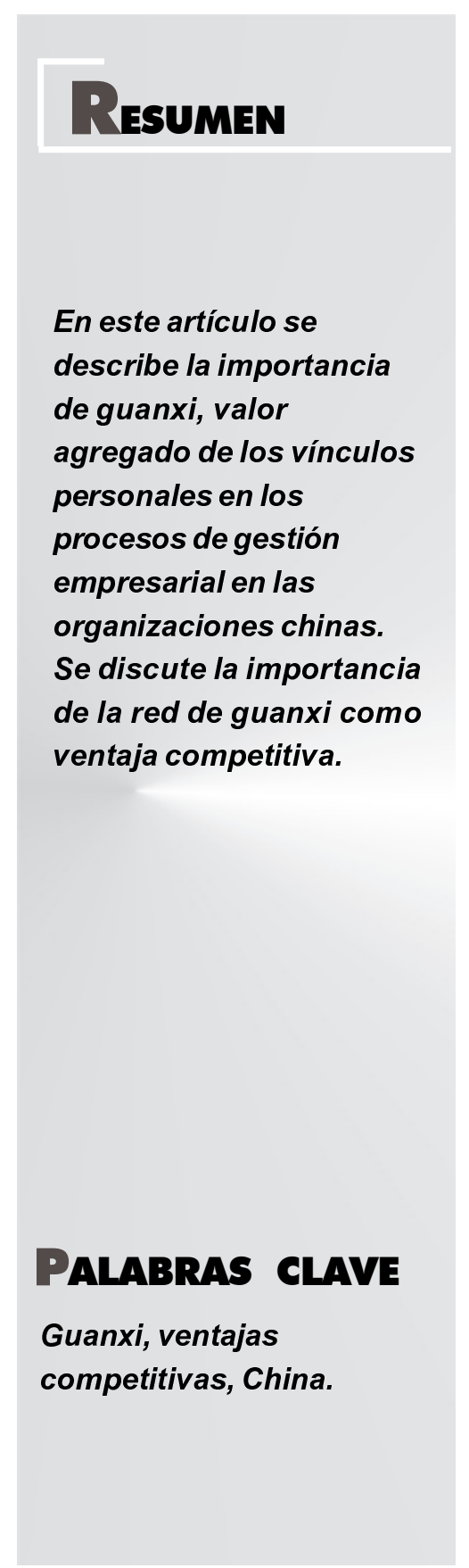

\footnotetext{
1 Guillermo S. Edelberg. DBA, profesor emérito Escuela de Negocios2 INCAE.

Agradezco al Dr. Jorge L. Krasuk, amigo y colega, el que me haya motivado a esta publicación.
} 
de investigación en las universidades rígidamente burocrático que tiene vínculos débiles con el sector privado.»

Las líneas anteriores me recordaron que los conferencistas y las publicaciones especializadas nos han dejado de «bombardear» con técnicas japonesas de management como círculos de calidad o just in time, por ejemplo, o palabras en japonés, como kaizen (mejoras continuas) o, una, algo siniestra, karoshi (muerte por agotamiento). Otra, kanban, fue mencionada en un concurso de oposición entre los aspirantes -me contaba entre ellos- a ocupar una cátedra. En aquella ocasión el conocer esta palabra parecía situar a los concursantes en las «fronteras del conocimiento»).

También me indujeron a pensar, por comparación, en China, el país actualmente "de moda». Aparte de Confucio y Sun Tzu y su El arte de la guerra, entre otros, se lee o escucha poco sobre sus prácticas de management, como ocurría con Japón. ¿Cómo manejan sus organizaciones los gerentes chinos? ¿Tienen alguna manera peculiar de dirigir a sus empresas, hacen esfuerzos por asimilar la experiencia ajena o ponen en práctica ambas opciones en forma simultánea?

La inquietud me llevó a revisar las publicaciones a mi alcance. ¿Qué encontré?

Vi referencias a temas tales como los cambios de los últimos 25 años, la transición de un manejo centralizado a otro descentralizado, la aparición de empresas pequeñas, el crecimiento de algunas de éstas y la aparición de programas de enseñanza de administración de empresas al estilo occidental (de los cuales el gobierno chino había establecido unos 60 hacia 2004). En especial, encontré menciones sobre guanxi, un enfoque que constituye algo así como un «común denominador» del management chino. ¿Qué es?

La palabra guanxi - se pronuncia guansí - se refiere a la relación, la conexión o el vínculo personal e intransferible existente entre dos personas, por medio

\section{A BStract}

This paper describes the meaning of guaxi, and added value to personal relationships in the management process in Chinese organizations. It is also discussed the importance of the guaxi (kind of networking) as a competitive advantage.

\section{EY WORDS}

Guanxi, competitive advantages, Chinese market. 
del cual se intercambian favores. Éstas pueden ser de distintos estatus sociales aunque, como es lógico, la de menor status tiene más dependencia con respecto a la otra.

El concepto así definido es sencillo; sin embargo, su manejo es sofisticado y un gerente extranjero que se radique en China debe aprender a planearlo, construirlo y cultivarlo. Su aplicación, importante en la vida personal, también lo es en el mundo de los negocios.

La base de guanxi puede tener su origen tanto en la familia, en un sentido amplio, como en las distintas actividades desarrolladas a lo largo de los años: estudios, trabajo o deporte, por ejemplo. Si bien el vínculo es intransferible, si A necesitara vincularse con C, buscará a $B$, quien forma parte de su red de guanxi, para que lo presente, porque, a su vez, éste incluye a $\mathrm{C}$ en su red.

Lo dicho no representa nada nuevo; pero «lo que guanxi tiene de especial en la sociedad china es su valor como herramienta: crea obligaciones recíprocas entre las partes con respecto a la adquisición de recursos» (E.W.K. Tsiang, Can guanxi be a source of sustained competitive advantage for doing business in China? The Academy of Managemenet Executive. Briarcliff Manor: mayo de 1998).

Un aspecto importante de guanxi es su nivel de intensidad el cual surge del compromiso emocional denominado ganqing -se pronuncia ganchín- desarrollado con el correr del tiempo. Otro se refiere a la reputación o imagen de una persona (mencionado en inglés como face): es mayor cuanto mayor y mejor sea su red de guanxi.

«El artículo recién mencionado dice lo siguiente:
Un dicho popular expresa que China es la tierra del guanxi. Nada puede hacerse sin éste. Una encuesta entre ejecutivos chinos de Hong Kong señaló que los empresarios creían que una importante cantidad de beneficios se derivan del establecimiento de una buena red de guanxi. Esto incluye llevar a cabo las operaciones de la empresa sin mayores sobresaltos, obtener información acerca de las políticas gubernamentales y conseguir autorizaciones administrativas. Otra encuesta indicó que es importante para las negociaciones comerciales.» (Tsiang, 1998).

Con el crecimiento de las organizaciones se comenzó a hablar de guanxi entre éstas; pero como su origen es siempre entre dos personas, las empresas están atentas a que la salida de uno de sus gerentes no perjudique su red de guanxi organizacional.

Mucho guanxi puede llevar a consecuencias indeseadas y hasta a abusos. Por ejemplo: un vendedor chino de una empresa extranjera vendía simultáneamente, sin conocimiento de sus superiores, productos elaborados por fabricantes locales. ¿Por qué? Porque las obligaciones de su red de guanxi le eran importantes. (W.R. Vanhonacker, When good guanxi turns bad, Harvard Business Review, abril de 2004).

Se cuenta que en una oportunidad MacDonald's alquiló por 20 años un local en una zona privilegiada de Beijing; pero tuvo que desalojarlo a los dos de ocuparlo porque un empresario de Hong Kong hizo valer su guanxi con un importante funcionario local.

A mediados de enero de 2006 un aviso publicado en un diario por una importante empresa multinacional decía, al ofrecer ésta sus servicios, lo siguiente: "Let's network». 
El aviso no le serviría de mucho en China.

Guanxi es más que networking.

\section{Guanxi: ¿una ventaja competitiva?}

El artículo anterior, titulado «» Guanxi es más que Networking»», sobre las prácticas de management en China, incluyó una explicación. Decía así:

«Los estudiosos del management en China han observado que un número significativo de empresas extranjeras, a veces asociadas con empresas locales, abrió allí representaciones pese a no planear inversiones importantes en un futuro inmediato. Una de las razones para explicar este hecho se refiere a la relevancia que la red de guanxi tiene tanto en la puesta en marcha como en el manejo de los negocios. La apertura de representaciones permite, entre otros objetivos, desarrollar redes de guanxi con la anticipación debida y -con un poco de suerte-antes que sus competidores.» (Vanhonacker, 2004)

Un autor lo expresa en forma más técnica: "guanxi se convierte en un ingrediente importante de la estrategia empresarial porque puede ayudar a establecer un posicionamiento estratégico específico en el medio competitivo chino. Por este motivo guanxi requiere una formulación estratégica propia y una puesta en práctica cuidadosa. Éstas deben estar alineadas con las de la empresa y, como todo activo, manejarse correctamente para evitar resultados no queridos.» (Vanhonacker, 2004).

\section{¿Es guanxi una fuente de ventaja competitiva?}

La respuesta no se encuentra con frecuencia en los contenidos de las revistas especializadas. E. W. K. Tsiang (1998), intenta ofrecerla para lo cual analiza el «recurso» guanxi tal como se lo hace con otros recursos de la empresa. Según dice, guanxi, para poder constituirse en una ventaja competitiva sostenible, debe ser valioso, poco común y difícil de imitar.

Su valor económico, la primera de estas tres características, se refiere a la posibilidad de que contribuya, por ejemplo, a mayores ventas o menores costos. También, a su contribución a la hora de sentarse a negociar. Menos visible es la contraprestación derivada de un favor recibido, que vendría a ser algo así como una especie de "cuenta a pagar». El autor recomienda hacer un análisis de costo-beneficio porque no es raro el caso en que el intercambio de favores o atenciones termine en pérdidas. Por ejemplo: un gerente chino de una empresa extranjera no recibió en su casa a representantes de sus proveedores locales ni aceptó sus regalos. Si desarrollaba guanxi de esta manera, iba a tener que aceptar los productos de menor calidad que los proveedores le habrían de suministrar.

Guanxi poco común, la segunda de las características, debe interpretarse como una red de guanxi difícil de establecer frente a la necesidad de relacionarse con numerosos e importantes funcionarios de la administración pública china. No cualquier empresa está en condiciones de hacerlo. Según E. W. K. Tsang, el autor del artículo que nos ocupa, «algunas grandes compañías de Hong Kong se prepararon para el cambio político que tuvo lugar en 1997 incorporando a sus organizaciones a hijos de funcionarios importantes que habrían de estar involucrados en el traspaso de soberanía». 
La dificultad en imitarse, la tercera característica, se refiere al hecho de que la competencia querrá imitar todo guanxi estimado exitoso, por lo que conviene oponer obstáculos al logro de este objetivo. Por ejemplo: guanxi desarrollado a lo largo de muchos años no podrá imitarse en un período breve.

La red de guanxi debe ser sostenible y mantenerse a lo largo del tiempo sin depender de los contactos personales de una persona que pueden perderse si ésta se aleja de la organización. El autor señala la conveniencia de que las empresas practiquen la auditoría de su red de guanxi.

Las características descriptas, en caso de lograrse, habrán de constituir una ventaja competitiva. No todos llegan a esta conclusión.

A mediados de 2004 tuvo lugar en Shanghai la reunión anual del Global Leadership Forum organizado por la Harvard Business School. En una de las sesiones, el profesor $F$. Oberholzer-Gee expuso las conclusiones que extrajo, junto con su colega, el profesor $\mathrm{T}$. Khanna, de un trabajo del Banco Mundial llevado a cabo mediante información obtenida en unas 3.900 empresas chinas. Un artículo resumió dichas conclusiones así:
«La importancia de las relaciones en la cultura china se extiende al mundo de las empresas, donde una simple frase expresa mucho: «Sin guanxino hay negocios». O sea: sin relaciones no hay negocios. El profesor Oberholzer-Gee hizo notar que las relaciones asumen mayor importancia en China porque contribuyen a subsanar las debilidades de las instituciones legales y de las reglamentaciones. ¿Les va mejor a las empresas que tienen relaciones estables con sus banqueros, clientes y proveedores?» (Alumni Bulletin, 2004).

«Nos sorprendió descubrir que no les va necesariamente mejor a las empresas que cuentan con relaciones de larga data» dijo Oberholzer-Gee. En realidad, las empresas chinas con un socio extranjero crecieron menos que aquellas que no lo tenían. «Decir que no se necesitan relaciones no sería correcto,» continuó diciendo. «Todo el mundo tiene relaciones porque son muy importantes; pero no se debe llegar a la conclusión de que las relaciones constituyen una ventaja competitiva. »

Sospecho que los especialistas y los empresarios que se radiquen en China van a discutir durante mucho tiempo si la red de guanxi constituye una fuente de ventajas competitivas o no.

\section{Bibliografía}

ALUMNI BULLETIN (2004). HBS. Boston: septiembre.

TSIANG, E. W. K. (1998). Can guanxi be a source of sustained competitive advantage for doing business in China? The Academy of Management Executive. Briarcliff Manor: mayo.

VANHONACKER, W.R. (2004). When good guanxi turns bad, Harvard Business Review, abril.

VANHONACKER, W. R. (2004). The China Business Review. Washington: mayo-junio. 